\title{
NUMERICAL AND EXPERIMENTAL STUDY OF A SOLAR WATER HEATER FOR ENHANCEMENT IN THERMAL PERFORMANCE
}

\author{
K. Vasudeva Karanth ${ }^{1}$, Madhwesh $\mathbf{N}^{2}$, Shiva Kumar ${ }^{3}$, Manjunath M.S ${ }^{4}$ \\ ${ }^{1}$ Corresponding Author, Department of Mechanical \& Mfg. Engineering, M. I. T., Manipal, Karnataka, India \\ ${ }^{2}$ Department of Mechanical \& Mfg. Engineering, Manipal Institute of Technology, Manipal, Karnataka, India \\ ${ }^{3}$ Department of Mechanical \& Mfg. Engineering, Manipal Institute of Technology, Manipal, Karnataka, India \\ ${ }^{4}$ Department of Mechanical \& Mfg. Engineering, Manipal Institute of Technology, Manipal, Karnataka, India
}

\begin{abstract}
Largest commercial application amongst the various solar collectors is the solar flat plate collectors mainly due to its simple design as well as low maintenance cost. Numerical analysis of the solar water heater which involves conduction and convection due to radiation heat transfer using Computational Fluid Dynamics (CFD) as a tool has not been the focus of study so far. It is generally understood that sinusoidal flow passage tends to increase turbulence which in turn increases convective heat transfer. The advantage of using straight absorber tube over sinusoidal absorber tube on the thermal behavior of the solar water heater needs to be explored as a design prescription. In the study presented in this paper it is noted from the experimental and numerical analysis that the straight tube configuration has better performance than that of sinusoidal pipe configuration.
\end{abstract}

Keywords: Sinusoidal tube, Solar water heater, Convective heat transfer, Computational fluid dynamics.

\section{INTRODUCTION}

Solar flat plate collectors even though produce lower temperature rise, they are simpler in design and have lower maintenance cost. Solar collector is a complex heat exchanger that transfers radiation heat from the sun to the working fluid. Kumar \& Rosen [2] explored the performance of an integrated solar water heater using corrugated absorber plate. The absorber plate surface is considered to be corrugated with small indentation depths. They results revealed that solar water heater had higher operating temperature for longer time as compared to the flat absorber plate.

Prasad et al [3] conducted an experimental study on a flat plate water heater with sun tracking mechanism. The found that the thermal efficiency increased by about $21 \%$.Varol and Oztop [4] numerically examined the fluid flow and heat transfer in a collector with wavy absorber plate. The results showed that higher Rayleigh number and aspect ratio increases the heat transfer while increasing the wavelength decreases the heat transfer. Karim and Hawlader [5] carried out an experimental analysis on $\mathrm{V}$-groove air heating system under the operating conditions of Singapore. They found that the V-corrugations provided improved thermal efficiency as compared to a flat plate collector.

Varol and Oztop [6] carried out a CFD analysis of natural convection heat transfer inside the inclined wavy solar collectors and flat-plate solar collectors. They found that the fluid flow and heat transfer are affected by the geometry of enclosure and augments the heat transfer as compared to the flat enclosure. Akpinar and Kocyigit [7] conducted an experimental analysis on a novel flat plate solar air heater fitted with several obstacles to provide turbulence in the fluid flow. They found that the presence of obstacles significantly increases the heat transfer. Gertzos and Caouris [8] conducted an experimental and numerical analysis on an integrated collector storage solar device with recirculation and established a validated three-dimensional CFD model. Wang et al. [9] conducted a numerical simulation on transpired solar air collector and found that the collector has significant advantages in the ventilation preheating area and also proves that CFD tools have their own advantages in the solar air collector research area. Selmi et al. [10] conducted a validated CFD model for flat plate solar water heater. Ho et al. [11] carried out an experimental and theoretical analysis of recyclic flat-plate solar water heater equipped with rectangle conduits. They found that the collector efficiency increases with increasing flow conduit aspect ratio and recycle ratio. Kumar and Prasad [12] found that use of twisted tape inserts inside the water tube increases the efficiency by $18-70 \%$ with a pressure drop of $87-132 \%$ as compared to ordinary collectors.

It is observed from the literature review of solar water heaters that numerical analysis of the solar water heater which involves conduction and convection due to radiation heat on the sine wave absorber tube using CFD has not been the focus of study so far. It is generally understood that sinusoidal flow passage tends to increase turbulence which in turn increases convective heat transfer. The advantage of using straight absorber tube over sinusoidal absorber tube on the performance of the solar water heater needs to be explored as a design prescription. Hence in this study a CFD analysis is carried out to explore the efficacy of sine wave absorber tube over straight absorber tube 


\section{NUMERICAL ANALYSIS}

\subsection{Geometry Description and Assumptions}

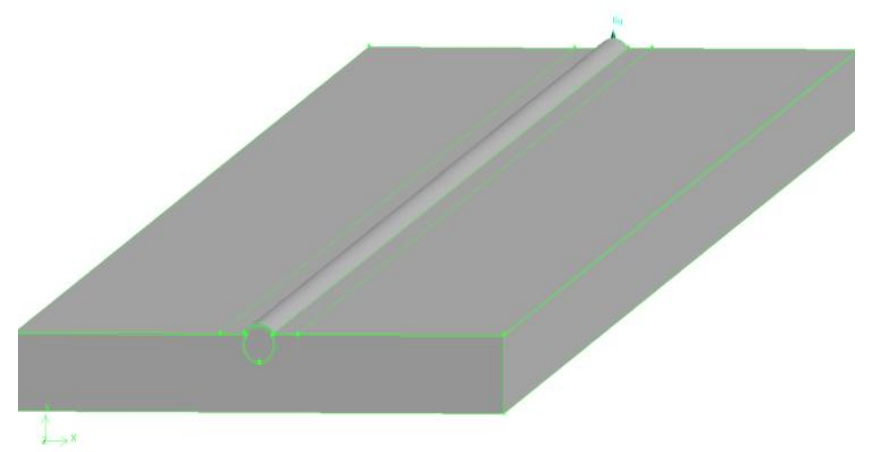

Fig.1. Straight tube configuration of solar water heater

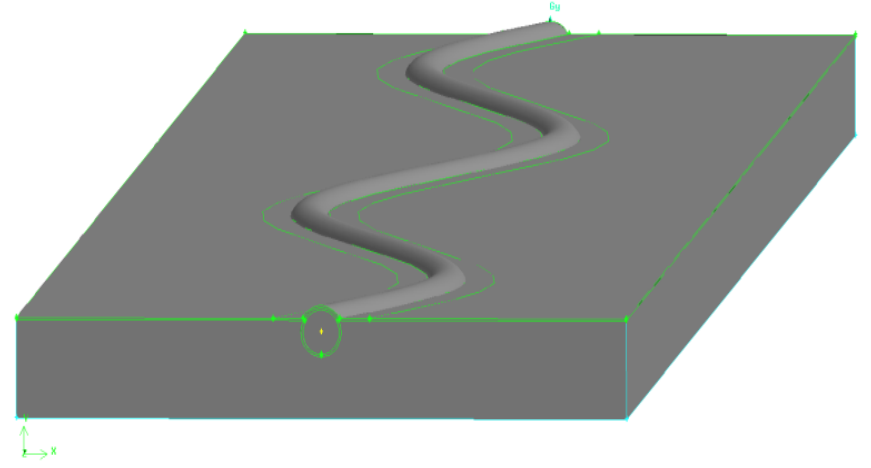

Fig.2. Sinewave configuration of solar water heater

The flow domain consists of an absorber plate of $1.2 \mathrm{~m}$ length, $195 \mathrm{~mm}$ wide and $0.5 \mathrm{~mm}$ thickness. An absorber tube of $12.5 \mathrm{~mm}$ diameter and $0.65 \mathrm{~mm}$ thickness is attached below the absorber plate. The absorber plate and the absorber tube are insulated with glass wool of $25 \mathrm{~mm}$ thickness. The water tube is attached to the absorber plate by placing it centrally with a small angle of lap. The first configuration adopted in the study is a straight absorber tube as shown in figure 1 . The second configuration is a tube of sine wave geometry having a wave length of $0.6 \mathrm{~m}$ and amplitude of $30 \mathrm{~mm}$ as shown in figure 2 . The assumptions made in the analysis are, a) Water is a continuous medium and incompressible. b) The flow is steady and possesses laminar flow characteristics, at lower velocity and turbulent characteristics at higher velocity. C) The thermal-physical properties of the absorber plate and the absorber tube are constant with respect to the operating temperature.

\subsection{Numerical Method}

Numerical simulation is carried out with steady state implicit pressure based solver using the Fluent 14.5 code [1]. The governing partial differential equations for mass and momentum are solved for the steady state flows. The pressure-velocity coupling is carried out using the SIMPLE algorithm [1]. Discretization is done using the second order upwind scheme.

\subsection{Mean Flow Equations}

All the equations are presented in Cartesian tensor notation.

Continuity:

$$
\frac{\partial}{\partial x_{i}}\left(\rho U_{i}\right)=0
$$

Momentum equation

$$
\frac{\partial}{\partial x_{j}}\left(\rho U_{i} U_{j}\right)=\frac{\partial P}{\partial x_{i}}+\frac{\partial}{\partial x_{j}}\left[\mu\left(\frac{\partial U_{i}}{\partial x_{j}}+\frac{\partial U_{j}}{\partial x_{i}}\right)-\rho \overline{u_{i} u_{j}}\right]
$$

Energy equation

$$
\frac{\partial}{\partial x_{j}}\left(\rho U_{i} T\right)=\frac{\partial}{\partial x_{j}}\left[\frac{\mu}{\operatorname{Pr}} \frac{\partial T}{\partial x_{j}}-\rho \overline{u_{i} t}\right]
$$

\subsection{Numerical Scheme}

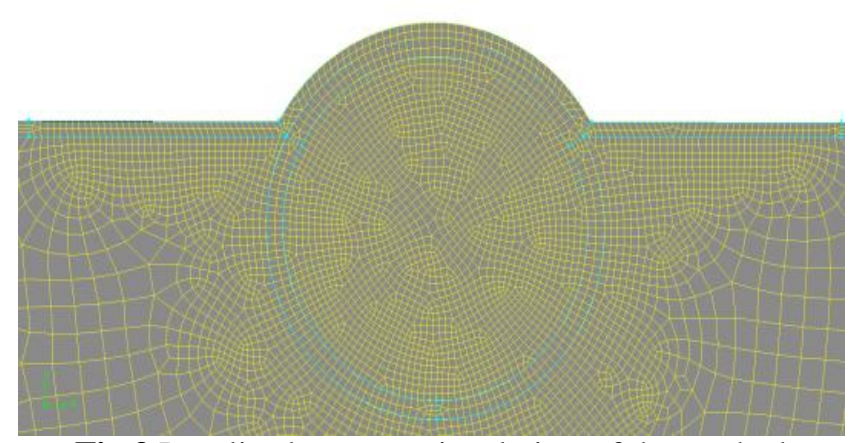

Fig.3 Localized cross sectional view of the meshed computational domain

The three dimensional computational domain is modeled using hex mesh and a localized view of the mesh is shown in Figure 3. The complete domain consists of 1.5 million elements which include the water, water tube absorber plate and insulating material. The grid independence test was performed to obtain an optimal mesh for the computational domain. It was found that further refinement of mesh size did not change the result by more than $1 \%$ which is taken here as the optimal mesh quality for computation.

Steady state simulation is carried out to establish the flow and thermal characteristics of the solar water heater models with straight and sinewave tube. Convergence was considered when all the scaled residuals fell below $10^{-5}$ in the computational domain.

\subsection{Boundary Conditions and Operating}

\section{Parameters}

A 'mass flow inlet' boundary condition is specified at the inlet and an 'outflow' condition is specified at the outlet for the water continuum. The mass flow rate for the numerical study is as obtained from the experimental study. Wall boundary conditions were used to bound fluid and solid 
regions. At the wall, no-slip and impermeability conditions are applied. The interface between the water and the absorber tube is defined as wall with coupled condition to effect conjugate heat transfer from absorber tube to the water. A standard $k-\varepsilon$ model is adopted in the analysis to take into account the turbulence that might occur in the flow domain.

In order to numerically establish the effectiveness of the two configurations of water heater adopted in the analysis, the numerical models are modeled with approximately the same number of elements and identical boundary conditions are applied. The performance parameters adopted for comparison of the two configurations are i) the Nusselt number $(\mathrm{Nu})$ and ii) the convective heat transfer coefficient (h). The temperature coefficient $\mathrm{C}_{\mathrm{T}}$ is calculated using Eq.(4) where, $T_{0}$ is the water inlet temperature. Length ratio for the flow path is taken as $\mathrm{L}_{\mathrm{r}}=1 / \mathrm{L}$, where $\mathrm{L}=1.2 \mathrm{~m}$.

$$
C_{T}=\frac{T-T_{0}}{T_{0}}
$$

\section{EXPERIMENTAL SETUP}

The solar water heater structure is fabricated using half inch thick plywood material and is $1.2 \mathrm{~m}$ long, $0.22 \mathrm{~m}$ wide and $0.05 \mathrm{~m}$ in height. The upper surface is made up of a $0.5 \mathrm{~mm}$ thick copper plate which is the absorber plate exposed to solar radiation. The absorber plate is painted black for absorbing the heat due to solar radiation. RTD (Resistance Temperature Detectors) type thermocouples are at the inlet, outlet and the absorber plate for measuring the water temperature and the absorber plate temperature. The heat flux that is incident on the absorber plate due to solar irradiation is measured using a Pyranometer. The experimentation was carried out between 1130 a.m. to 1.30 p.m. when the average heat flux as recorded by the pyranometer was noted to be $810 \mathrm{~W} / \mathrm{m}^{2}$. The experiments were carried out for 4 different mass flow rates of $20 \mathrm{ml} / \mathrm{min}$, $63 \mathrm{ml} / \mathrm{min}, 198 \mathrm{ml} / \mathrm{min}$ and $360 \mathrm{ml} / \mathrm{min}$.

\section{RESULTS AND DISCUSSION}

The numerical, analysis is carried out after the experimental study of the two collectors is conducted and the mass flow rates adopted in the experimental study are taken as the input for the numerical analysis.

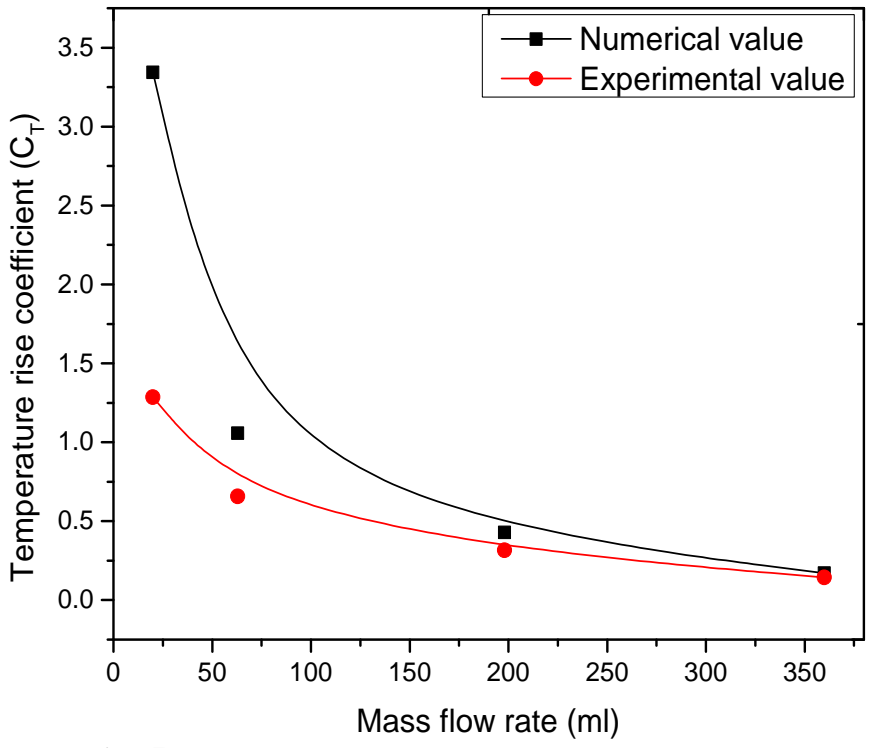

Fig. 5 Absorber fluid temperature rise coefficient corresponding to various mass flow rates for sine wave tube configuration

Fig. 4 shows the validation plot for the temperature rise coefficients of the absorber fluid corresponding to the four mass flow rates for straight tube configuration. It can be observed from this graph that at lower mass flow rates the experimental and numerical values of the absorber fluid temperature coefficients vary with a large difference. However at higher mass flow rates, the temperature coefficients for experimental and numerical analysis come closer with a matching trend line. The same trend is observed for sine wave configuration as can be seen in Fig. 5. The large gap between the numerical and experimental results at lower mass flow rates can be attributed to the heat loss that takes place across the boundaries which are not accounted in the numerical analysis which assumes ideal insulating conditions.

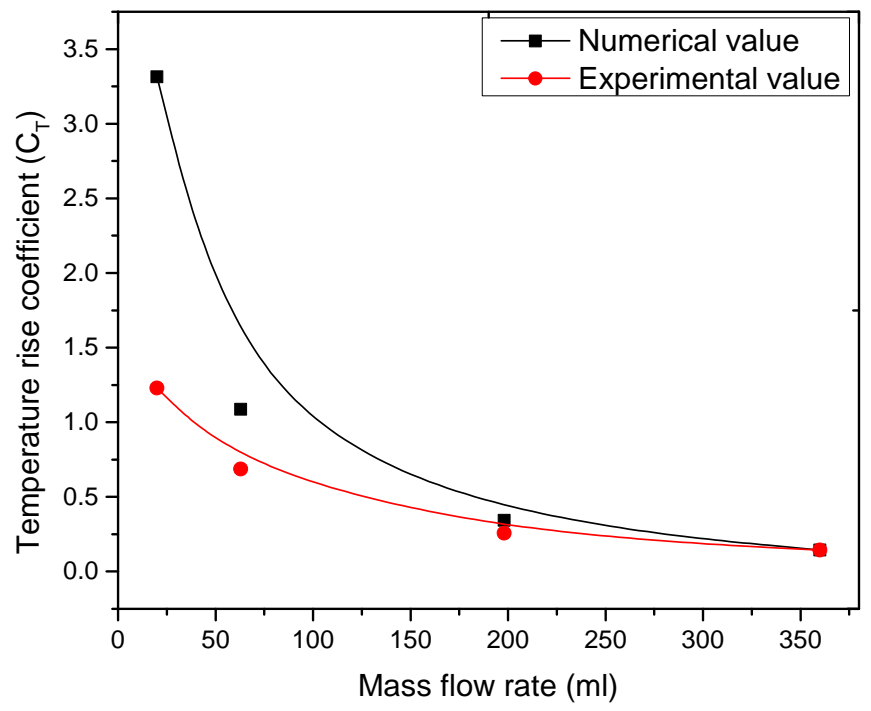

Fig. 4 Absorber fluid temperature rise coefficient corresponding to various mass flow rates for straight tube configuration 


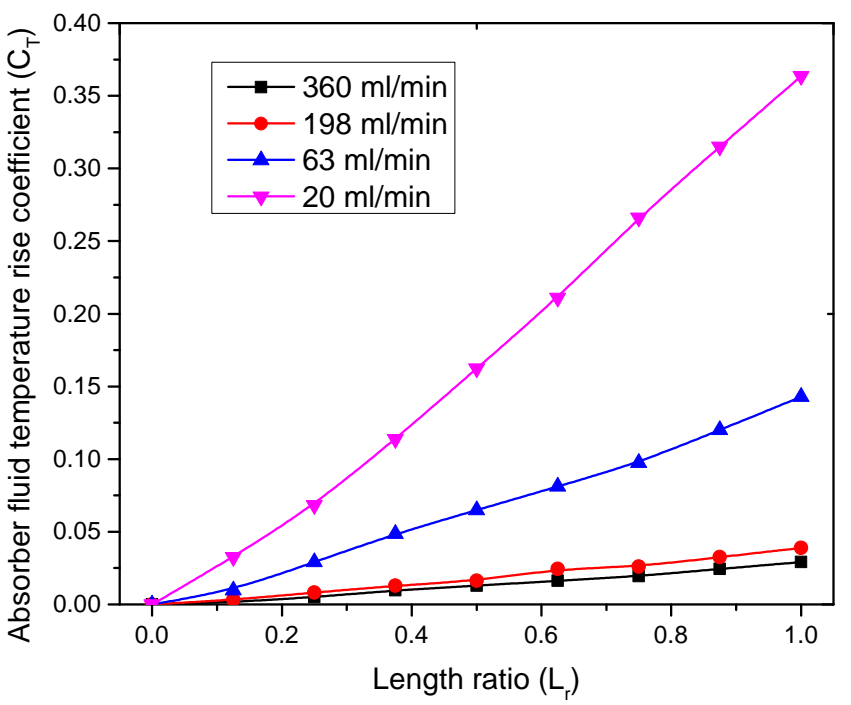

Fig. 6 Absorber fluid temperature rise coefficient along the flow length of the tube for straight tube configuration

The simulation is carried out at 4 different mass flow rates and fig 6 shows the plot for temperature rise coefficient along the flow length of the absorber tube. From this plot it is seen that, as the absorber plate is uniformly heated corresponding to various mass flow rates, the fluid in the absorber tube gets differentially heated with significant temperature gradient for lower mass flow rate followed by a smaller temperature gradient for higher mass flow rates. The numerical analysis is carried out so as to meet the convergence criteria and the two configurations are compared in terms of its thermal performance. The numerical results for the two configurations are presented in terms of the Nusselt number $(\mathrm{Nu})$ and the convective heat transfer coefficient (h) as shown in figures 7 and 8 .

It can be observed from the bar diagrams of figure 7 that the Nusselt number for configuration with straight absorber tube is higher than that of the sine wave tube configuration for the given mass flow rate and heat flux on the absorber plate. This can be attributed to the fact that the fluid in the sine wave tube has to traverse a larger distance compared to that of straight tube configuration for the given mass flow rate and hence reducing the speed of the flow. This leads to a lower convective heat transfer that is taking place to the fluid (fig 8.) and hence reducing the Nusselt number.

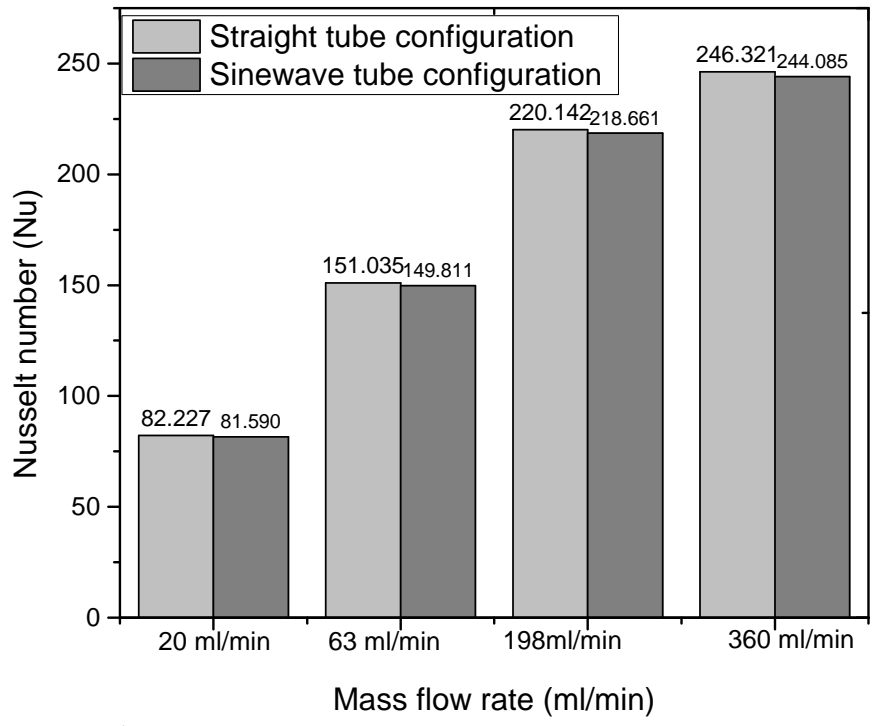

Fig.7. Bar charts of Nusselt number for the two configurations.

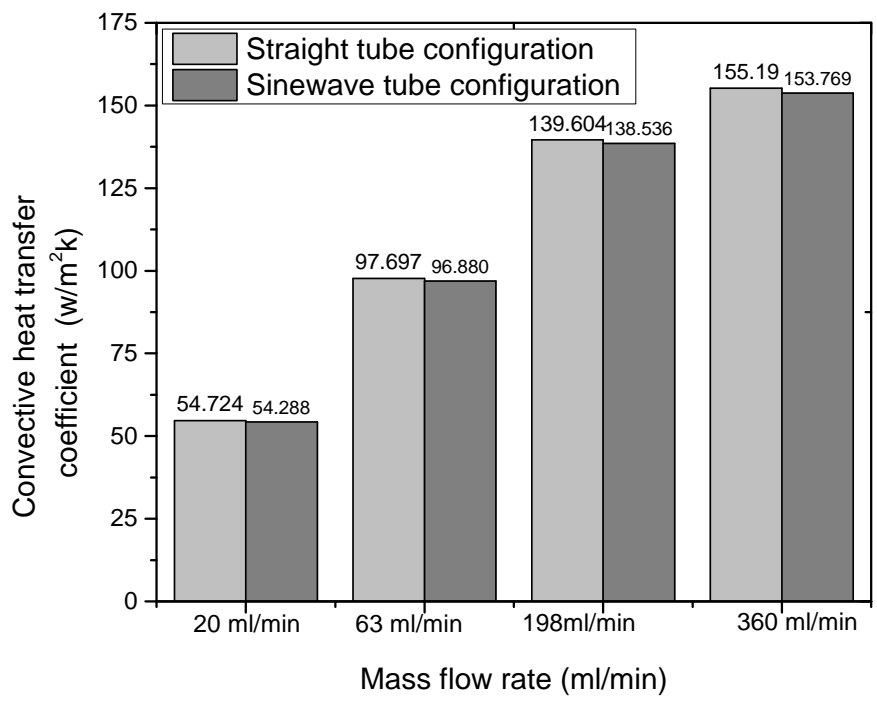

Fig.8. Bar charts of convective heat transfer coefficients for the two configurations.

Fig.9 (a) and Fig.9(b) show temperature contour plots of the absorber plate for sine wave and straight tube configurations at a lower mass flow rate of $20 \mathrm{ml} / \mathrm{min}$. This is in comparison with the temperature contour plot for the same configuration at higher mass flow rate of $360 \mathrm{ml} / \mathrm{min}$ as shown in figures $10 \mathrm{a}$ and $10 \mathrm{~b}$.

It can be noted from these plots that the heat transfer from the absorber plate to the absorber tube is uniform in case of straight tube configuration whereas for sinewave configuration the heat transfer is more near the absorber tube and hence a non-uniform distribution of temperature is observed for the absorber plate. This non uniform heat transfer that takes place from absorber plate to the absorber tube can also be attributed to the lower Nusselt number and convective heat transfer for the sinewave tube configuration. 


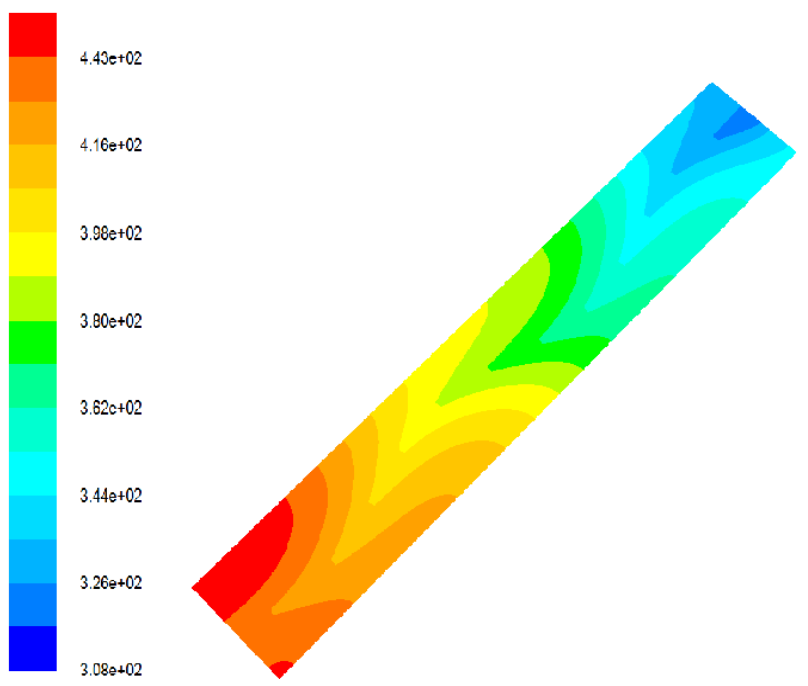

Fig.9(a). Absorber plate temperature contour plot for sinusoidal tube configuration at $20 \mathrm{ml} / \mathrm{min}$

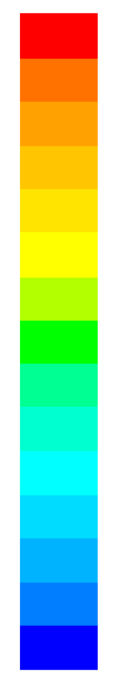

$4.39 \mathrm{e}+02$
$4.30 \mathrm{e}+02$
$4.21 \mathrm{e}+02$
$4.13 \mathrm{e}+02$
$4.04 \mathrm{e}+02$
$3.95 \mathrm{e}+02$
$3.87 \mathrm{e}+02$
$3.78 \mathrm{e}+02$
$3.69 \mathrm{e}+02$
$3.60 \mathrm{e}+02$
$3.52 \mathrm{e}+02$
$3.43 \mathrm{e}+02$
$3.34 \mathrm{e}+02$
$3.25 \mathrm{e}+02$
$3.17 \mathrm{e}+02$
$3.08 \mathrm{e}+02$

Fig.9(b). Absorber plate temperature contour plot for straight tube configuration at $20 \mathrm{ml} / \mathrm{min}$
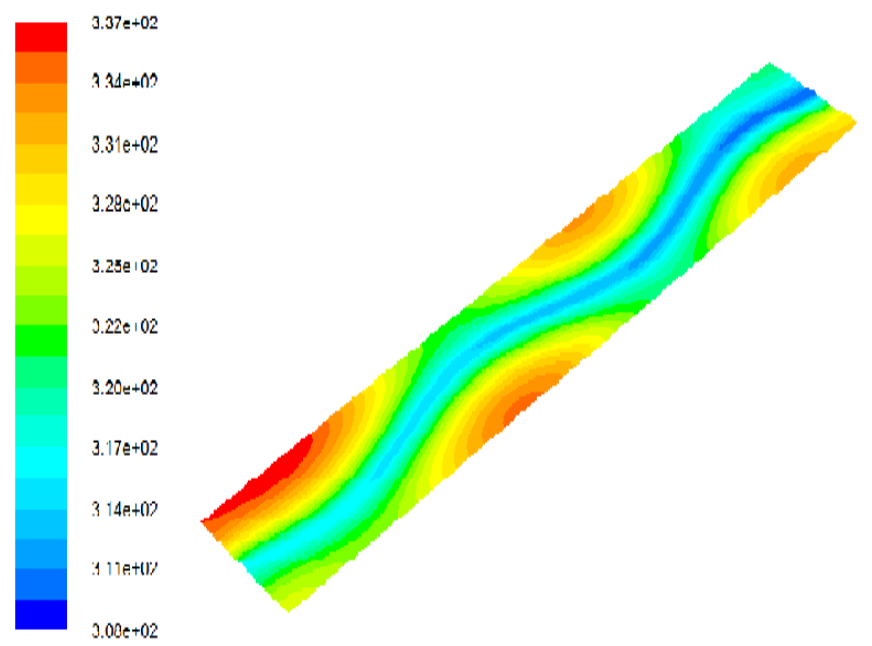

Fig.10(a). Absorber plate temperature contour plot for sinusoidal tube configuration at a mass flow rate of 360 $\mathrm{ml} / \mathrm{min}$
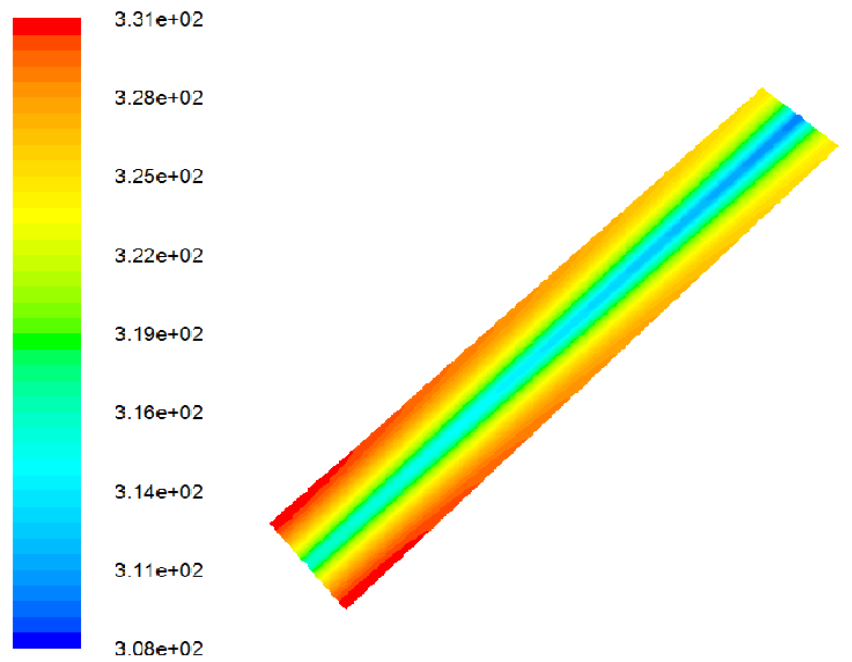

Fig.10(b). Absorber plate temperature contour plot for straight tube configuration at $360 \mathrm{ml} / \mathrm{min}$

\section{CONCLUSION}

Numerical study helps in understanding the complex heat transfer phenomena that takes place in a solar water heater and helps in quantifying the thermal performance which is otherwise not possible through experimentation due to the small difference in the temperatures outputs for the two comparable configurations. The following conclusions can be drawn from the numerical study.

- The Nusselt number for the straight tube configuration is higher than that of sine wave tube configurations of solar water heater for the given identical boundary conditions.

- The convective heat transfer coefficient is higher for straight tube configuration for all the mass flow rates compared to sine wave configuration.

- Non uniform heating of the absorber plate takes place for sine wave configuration.

Hence as a design prescription, it can be perceived that the straight absorber tube configuration has a better heat transfer capability compared to sine wave absorber tube configuration.

\section{ACKNOWLEDGEMENTS}

The computational facilities were provided by the Department of Mechanical and Manufacturing Engineering, Manipal Institute of Technology, Manipal, India which is appreciatively acknowledged.

\section{NOMENCLATURE}

$\mathrm{T}$ Temperature

$\mathrm{C}_{\mathrm{T}}$ Temperature rise coefficient

L Length of the collector

$\mathrm{L}_{\mathrm{r}} \quad$ Non-dimensional collector length (x/L)

U Velocity

$\rho \quad$ Density

$\mu \quad$ Viscosity

$\mathrm{P}_{\mathrm{r}} \quad$ Prandtl Number

$\mathrm{Nu} \quad$ Nusselt number 


\section{REFERENCES}

[1]. ANSYS Fluent 14.5 User's manual, Ansys Inc. (2013)

[2]. Kumar, A. Prasad, B.N., "Investigation of twisted tape inserted solar water heaters-heat transfer, friction factor and thermal performance results" Journal of Renewable Energy, Volume 19, pp. 379-398.. 2000.

[3]. Prasad, P.R., Byregowda, H.V., and Gangavati, P.B., "Experiment Analysis of Flat Plate Collector and Comparison of Performance with Tracking Collecto",. European Journal of Scientific Research, 40(1), pp. 144 $155,2010$.

[4]. Varol, Y. \& Oztop, H.F., "Buoyancy induced heat transfer and fluid flow inside a tilted wavy solar collector. Building and Environment, Volume 42, pp. 2062-2071, 2007.

[5]. Karim, A. Hawlader, M.N.A., "Performance evaluation of a v-groove solar air collector for drying applications", Applied Thermal Engineering, Volume 26, pp. 121-130, 2006.

[6]. Varol, Y. and Oztop, H.F., "A comparative numerical study on natural convection in inclined wavy and flat-plate solar collectors", Building and Environment, Volume 43, pp. 1535-1544, 2008.

[7]. Akpinar, E.K. Kocyigit, F., "Experimental investigation of thermal performance of solar air heater having different obstacles on absorber plates", International Communications in Heat and Mass Transfer, Volume 37(4), pp. 416-421. 2010.

[8]. Gertzos, K.P. and Caouris, Y.G., "Experimental and computational study of the developed flow field in a flat plate integrated collector storage (ICS) solar device with recirculation", Experimental Thermal and Fluid Science, Volume 31, pp. 1133-1145, 2007.

[9]. Wang, C., Guan, Z., Zhao, X., and Wang, D., "Numerical Simulation Study on Transpired Solar Air Collector" Renewable Energy Resources and a Greener Future, Volume 8, pp 3-4, 2006.

[10]. Selmi, M., Al-Khawaja, M.J., and Marafia, A., “ Validation of CFD simulation for flat plate solar energy collector", Renewable Energy, Volume 33, pp. 383-387, 2008,

[11]. Ho, C., Chen, T., and Tsai, C., "Experimental and theoretical studies of re-cyclic flat-plate solar water heaters equipped with rectangle conduits", Renewable Energy, Volume 35(10), pp. 2279-2287, 2010.

[12]. Kumar, A. and Prasad, B.N., "Investigation of twisted tape inserted solar water heaters-heat transfer friction factor and thermal performance results", Renewable Energy, Volume 19, pp. 379-398, 2000.

\section{BIOGRAPHIES}

Dr. K. Vasudeva Karanth is working as a faculty in the department of mechanical and manufacturing department of Manipal Institute of Technology. Manipal 576104. Email: kv.karanth@manipal.edu
Mr. Madhwesh N. is working as a faculty in the department of mechanical and manufacturing department of Manipal Institute of Technology. Manipal 576104. email: madhwesh.n@gmail.com

Dr. Shiva Kumar is working as a faculty in the department of mechanical and manufacturing department of Manipal Institute of Technology. Manipal 576104. Email:shiva_katipalla@yahoo.co.in

Mr. Manjunath M.S. is working as a faculty in the department of mechanical and manufacturing department of Manipal Institute of Technology. Manipal 576104. Email: manjunathnitc@gmail.com 